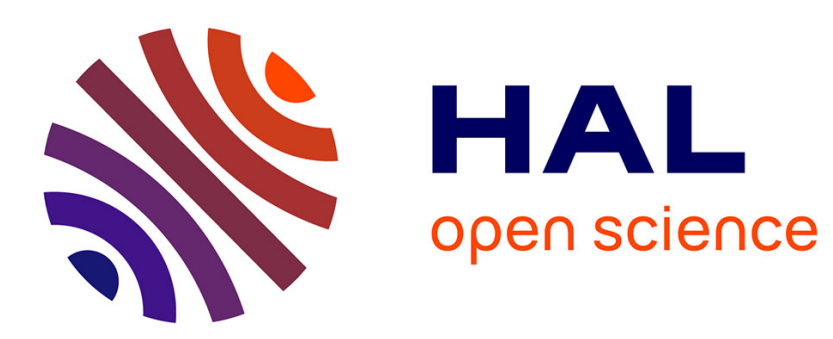

\title{
Spark and plasma in spark plasma sintering of rigid ceramic nanoparticles: A model system of YAG
}

Rachel Marder, Claude Estournès, Geoffroy Chevallier, Rachman Chaim

\section{To cite this version:}

Rachel Marder, Claude Estournès, Geoffroy Chevallier, Rachman Chaim. Spark and plasma in spark plasma sintering of rigid ceramic nanoparticles: A model system of YAG. Journal of the European Ceramic Society, 2014, vol. $35\left(\mathrm{n}^{\circ}\right.$ 1), pp. 211-218. 10.1016/j.jeurceramsoc.2014.08.001 . hal01451094

\section{HAL Id: hal-01451094 \\ https://hal.science/hal-01451094}

Submitted on 31 Jan 2017

HAL is a multi-disciplinary open access archive for the deposit and dissemination of scientific research documents, whether they are published or not. The documents may come from teaching and research institutions in France or abroad, or from public or private research centers.
L'archive ouverte pluridisciplinaire HAL, est destinée au dépôt et à la diffusion de documents scientifiques de niveau recherche, publiés ou non, émanant des établissements d'enseignement et de recherche français ou étrangers, des laboratoires publics ou privés. 


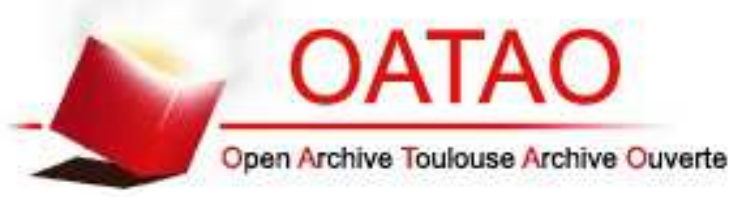

\section{Open Archive TOULOUSE Archive Ouverte (OATAO)}

OATAO is an open access repository that collects the work of Toulouse researchers and makes it freely available over the web where possible.

This is an author-deposited version published in : http://oatao.univ-toulouse.fr/ Eprints ID : 16587

To link to this article : DOI:10.1016/j.jeurceramsoc.2014.08.001 URL : http://dx.doi.org/10.1016/j.jeurceramsoc.2014.08.001

To cite this version : Marder, Rachel and Estournès, Claude and Chevallier, Geoffroy and Chaim, Rachman Spark and plasma in spark plasma sintering of rigid ceramic nanoparticles: A model system of YAG. (2014) Journal of the European Ceramic Society, vol. 35 ( $\mathrm{n}^{\circ}$ 1). pp. 211-218. ISSN 0955-2219

Any correspondence concerning this service should be sent to the repository administrator: staff-oatao@ listes-diff.inp-toulouse.fr 


\title{
Spark and plasma in spark plasma sintering of rigid ceramic nanoparticles: A model system of YAG
}

\author{
R. Marder ${ }^{\mathrm{a}, *}$, C. Estournès ${ }^{\mathrm{b}, \mathrm{c}}$, G. Chevallier ${ }^{\mathrm{b}, \mathrm{c}}$, R. Chaim ${ }^{\mathrm{a}}$ \\ ${ }^{a}$ Department of Materials Science and Engineering, Technion - Israel Institute of Technology, Haifa 32000, Israel \\ ${ }^{\mathrm{b}}$ Université de Toulouse, UPS, INP, Institut Carnot Cirimat, 118, route de Narbonne, F-31062 Toulouse Cedex 9, France \\ ${ }^{\mathrm{c}}$ CNRS, Institut Carnot Cirimat, F-31062 Toulouse, France
}

\begin{abstract}
Yttrium aluminum garnet (YAG) nano-particles were spark plasma sintered between $1100{ }^{\circ} \mathrm{C}$ and $1400{ }^{\circ} \mathrm{C}$ under $2-100 \mathrm{MPa}$ pressure without isothermal treatments. The span of relative density between $48 \%$ and $99 \%$ enabled microstructural examination at different stages of the densification. Electron microscopy examination showed material jets with amorphous character connecting between the spherical nano-particles, which were related to surface melting. Aligned nano-particles within the nano-clusters, apparently affected by high local electric fields, were observed in the partially dense microstructure. Rapid densification from $1200^{\circ} \mathrm{C}$ was related to densification by nano-particle sliding and rotation assisted by surface softening. The observed microstructural features were discussed with respect to sparking and plasma formation during the SPS. The occurrence of plasma was explained by means of the plasma formation- plastic deformation diagram.
\end{abstract}

(C) 2014 Elsevier Ltd. All rights reserved.

Keywords: Plasma; Spark plasma sintering; Densification; Powder consolidation; YAG

\section{Introduction}

Spark plasma sintering (SPS) and other electric field assisted sintering techniques become more widespread for rapid fabrication of simple- and complex-shape ceramic parts (see review ${ }^{1}$ ). This is evidenced by the many patents registered in this field in recent years. ${ }^{2}$ Therefore, correct application of these techniques for efficient fabrication of the ceramic articles with controlled microstructure and properties become high priority. This necessitates determination of the sintering and densification mechanisms active during the SPS, with respect to the composition and microstructure of the ceramic powder and the process parameters. Several different atomistic mechanisms were proposed for the rapid sintering, densification, and grain

\footnotetext{
* Corresponding author. Tel.: +972 4 8294290; fax: +972 48295677. E-mail addresses: rachelma@technion.ac.il, rachel.marder@gmail.com (R. Marder).
}

growth (or its inhibition) in nano-ceramic powders. ${ }^{3-9}$ Tokita was among the first to point out that spark and plasma can also be active in non-conducting ceramics. ${ }^{6,10}$ The debate about the presence or lack of sparking and plasma in non-conducting ceramic compacts has been challenged by the local melting and material jets reported in several different ceramics subjected to SPS. ${ }^{11-13}$ Recently, a simple model for discharge and plasma formation during the SPS was put forward, using the percolative nature of the electric current in the granular dielectrics. ${ }^{14}$ Two onset temperatures for activation of either plastic deformation or enhanced diffusion via particle surface melting/softening due to plasma, were determined; the lower temperature among the two determines the densification mechanism to be active first. The enhanced shrinkage in LiF microcrystals at pressures below the yield stress was consistent with these expectations for spark discharge and plasma heating at low pressures and temperatures. $^{15}$

The present paper reports the densification of YAG as a rigid model system for nano-particle compacts subjected to SPS with 
Table 1

The SPS conditions and specimens final densities.

\begin{tabular}{|c|c|c|c|c|}
\hline nc-YAG powder & SPS temperature $\left[{ }^{\circ} \mathrm{C}\right]$ & Pressure $[\mathrm{MPa}]$ & Final relative density [\%] & Grain size $[\mathrm{nm}]$ \\
\hline \multirow{11}{*}{ As received (AR) } & 1100 & 2 & 45.5 & \multirow{5}{*}{$90 \pm 33$} \\
\hline & 1100 & 32 & 51.8 & \\
\hline & 1100 & 64 & 54.6 & \\
\hline & 1100 & 100 & 60.1 & \\
\hline & 1200 & 2 & 43.7 & \\
\hline & 1200 & 100 & 61.9 & $92 \pm 43$ \\
\hline & 1250 & 100 & 67.7 & $96 \pm 38$ \\
\hline & 1300 & 100 & 73.9 & $115 \pm 34$ \\
\hline & 1350 & 100 & 87.7 & $138 \pm 41$ \\
\hline & 1400 & 2 & 70.8 & \\
\hline & 1400 & 100 & 99.0 & $325 \pm 121$ \\
\hline \multirow{2}{*}{ Heat treated $(\mathrm{HT})$} & 1100 & 2 & 46.1 & \\
\hline & 1100 & 100 & 50.8 & \\
\hline
\end{tabular}

clear microstructure evidence for surface melting via plasma. The occurrence of discharge spark followed by plasma heating was analyzed following a percolative current model in granular dielectric compacts.

\section{Experimental}

Pure commercial nano-crystalline Yttrium Aluminum Garnet (nc-YAG) powder (Nanocerox, USA) with spherical morphology and a mean crystallite size (diameter) of $70 \pm 50 \mathrm{~nm}$ was used. The powder was used in the as-received form (AR-powder) and after heat treatment (HT-powder) for $2 \mathrm{~h}$ in air at $1000^{\circ} \mathrm{C}$.

Discs of $8 \mathrm{~mm}$ in diameter were fabricated using the SPS unit (Dr. Sinter, SPS 2080) at the Nationale CNRS de Frittage Flash PNF2/CNRS in Toulouse. For all the sintering experiments the powders were poured into the graphite die without further pressing, thus the green density is close to the tap density of the powders. The green compact was isolated from the die wall and the punches using graphite foils (Grafoil).

The SPS experiments were conducted at different temperatures (between $1100{ }^{\circ} \mathrm{C}$ and $1400{ }^{\circ} \mathrm{C}$ ) and pressures (2-100 MPa) using the AR and the HT powders. The various sintering conditions and the resultant final densities were summarized in Table 1. The starting temperature for all SPS experiments was $600{ }^{\circ} \mathrm{C}$; when this temperature was stabilized ( $\sim 3$ min after turning on the SPS current-voltage) the desired uniaxial pressure was applied. The temperature was raised under maximal load at a constant heating rate of $100{ }^{\circ} \mathrm{C} \mathrm{min}^{-1}$ to the final SPS temperature. The process was stopped at the final SPS temperature by releasing the pressure and cooling the system (by turning off the current-voltage), without isothermal holding time at the final SPS temperature. Pulse duration of $3.3 \mathrm{~ms}$ and a vacuum level of 2-3 Pa were used. The SPS parameters such as voltage, current, temperature, pressure, ram displacement and ram displacement rate were recorded during the process.

In order to confirm or dismiss significant diffusion processes at the starting temperature of $600{ }^{\circ} \mathrm{C}$ three green nc-YAG specimens were prepared by cold isostatic pressing (CIP) under $210 \mathrm{MPa}$ pressure, followed by heat treatments for $1 \mathrm{~h}$ in air at $500{ }^{\circ} \mathrm{C}, 600^{\circ} \mathrm{C}$, and $700{ }^{\circ} \mathrm{C}$.
The final densities were measured by weighing and using the Archimedes method with distilled water medium. The linear shrinkage and temporary relative density of the compacts were calculated using the dimension and densities of the specimens after the SPS process and according to the ram displacement. The effects of the graphite die assembly on the displacement was considered and treated according to the procedure described elsewhere. ${ }^{16}$

The microstructure of the powder and the specimens was characterized using high resolution scanning electron microscope (HRSEM, Zeiss Ultra Plus FEG SEM equipped with EDS) operated at $2-4 \mathrm{kV}$, and transmission electron microscope (TEM, FEI Tecnai $G^{2}$ T20) operated at $200 \mathrm{kV}$. Specimens for TEM were prepared by conventional thinning and dimpling, followed by Ar-ion milling to electron transparency. A thin carbon coating was applied to most of the specimens to minimize charging effects in SEM and TEM. The grain size was determined from HRSEM images, where at least 200 grains were counted for each specimen. The powders particle size was measured using the TEM images. X-ray diffraction (XRD) was used for structure analysis using X-ray diffractometer (Rigaku SmartLab) equipped with monochromated $\mathrm{Cu} \mathrm{K} \alpha$ radiation, and operated at $40 \mathrm{kV}$ and $40 \mathrm{~mA}$; a scanning speed of $0.015^{\circ} \mathrm{s}^{-1}$ was used. Differential scanning calorimeter - DSC (Labsys 1600, Setaram) was used to characterize the thermal behavior of the powder, using the heating rate of $10^{\circ} \mathrm{C} \mathrm{min}^{-1}$.

\section{Results}

The YAG nano-powders were characterized using XRD and electron microscopy. The XRD spectrum of the as-received (AR) powder showed peaks of the Yttrium Aluminum Perovskite - $\mathrm{YAlO}_{3}$ (YAP) phase (JCPDS-00-54-0621) (Fig. 1). A small peak at $30.5^{\circ}$ corresponding either to hexagonal $\mathrm{Y}_{2} \mathrm{O}_{3}$ (JCPDS$00-020-1412$ ) or a new YAG phase ${ }^{17}$ is present, probably as residue of the powder manufacturing process by liquid flame spray pyrolysis. However, the fraction of this impurity phase was estimated to be less than $3.5 \mathrm{vol} \%$. Heat treatment of the as-received powder for $2 \mathrm{~h}$ in air at $1000{ }^{\circ} \mathrm{C}$ resulted in cubic YAG phase (JCPDS-33-0040) (Fig. 1), revealing that the phase 


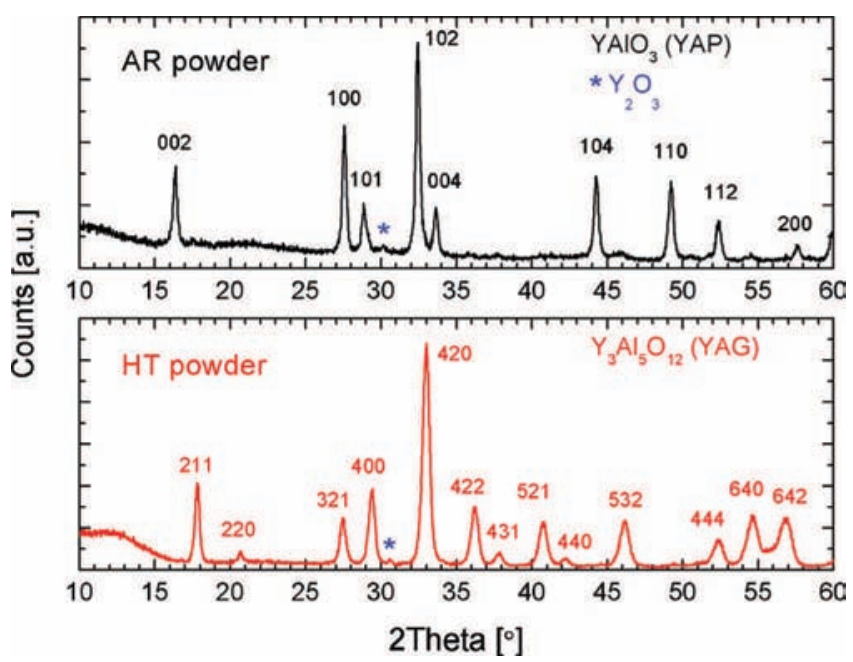

Fig. 1. XRD of the as-received (AR) and heat treated (HT) powder. Heat treatment led to phase transformation of the Perovskite phase of yttrium aluminum oxide (YAP) into the cubic garnet phase (YAG). The small peaks in the AR powder refer to the residual cubic YAG.

transformation went almost to completion. The AR powder had a particle size $70 \pm 50 \mathrm{~nm}$, measured using the TEM images (Fig. 2a). Part of the particles revealed an amorphous character, using tilting experiments in TEM. Some changes were observed in the particle size after the heat treatment, especially the smallest particles disappeared. However, well developed necks were found between the individual particles (Fig. 2b). DSC of the AR powder (not shown here) revealed exothermic peaks at $894^{\circ} \mathrm{C}$, $1087^{\circ} \mathrm{C}$ and $1241^{\circ} \mathrm{C}$. The first peak at $894^{\circ} \mathrm{C}$ corresponds to the crystallization of cubic $\mathrm{YAG}^{18,19}$ while the second peak at $1087^{\circ} \mathrm{C}$ is related to phase transformation of YAP into YAG. ${ }^{19,20}$ The peak at $1241^{\circ} \mathrm{C}$ was also reported by heating of pure YAG but its origin is unknown. ${ }^{21}$

The density and temperature changes during the SPS heating of the $\mathrm{AR}$ powder to $1400^{\circ} \mathrm{C}$ at 2 and $100 \mathrm{MPa}$ pressures were shown in Fig. 3a. The shrinkage profiles of these specimens are representative for all the specimens fabricated with the AR powder, since all experienced similar heating and pressure application regimes, albeit with different final temperatures. Application of $100 \mathrm{MPa}$ pressure led to the immediate shrinkage. This first shrinkage in the still un-sintered powder most probably occurs by rearrangement processes only, without plastic deformation, due to the high yield stress of YAG. The lower pressure of $2 \mathrm{MPa}$, which is practically the holding pressure during the SPS, led to almost no shrinkage by compaction. Further increase in density was observed at temperatures around $950{ }^{\circ} \mathrm{C}$ (i.e. 370 s), however this shrinkage ceased around $1060^{\circ} \mathrm{C}$ (i.e. $480 \mathrm{~s}$ ). This further shrinkage was hindered between $1060^{\circ} \mathrm{C}$ and $1200^{\circ} \mathrm{C}$ due to phase transformation of YAP to YAG phase, which was accompanied by a volume increase of $\sim 17 \%$ that balanced further densification. During this transformation a small increase in the pressure was recorded for all specimens (red dash-dotted curves in Fig. 3a).

At $1200{ }^{\circ} \mathrm{C}$ (i.e. $560 \mathrm{~s}$ ) the shrinkage continued again, irrespective of the applied pressure. The highest shrinkage rate was noted between $1200^{\circ} \mathrm{C}$ and $1400^{\circ} \mathrm{C}$, where the change in
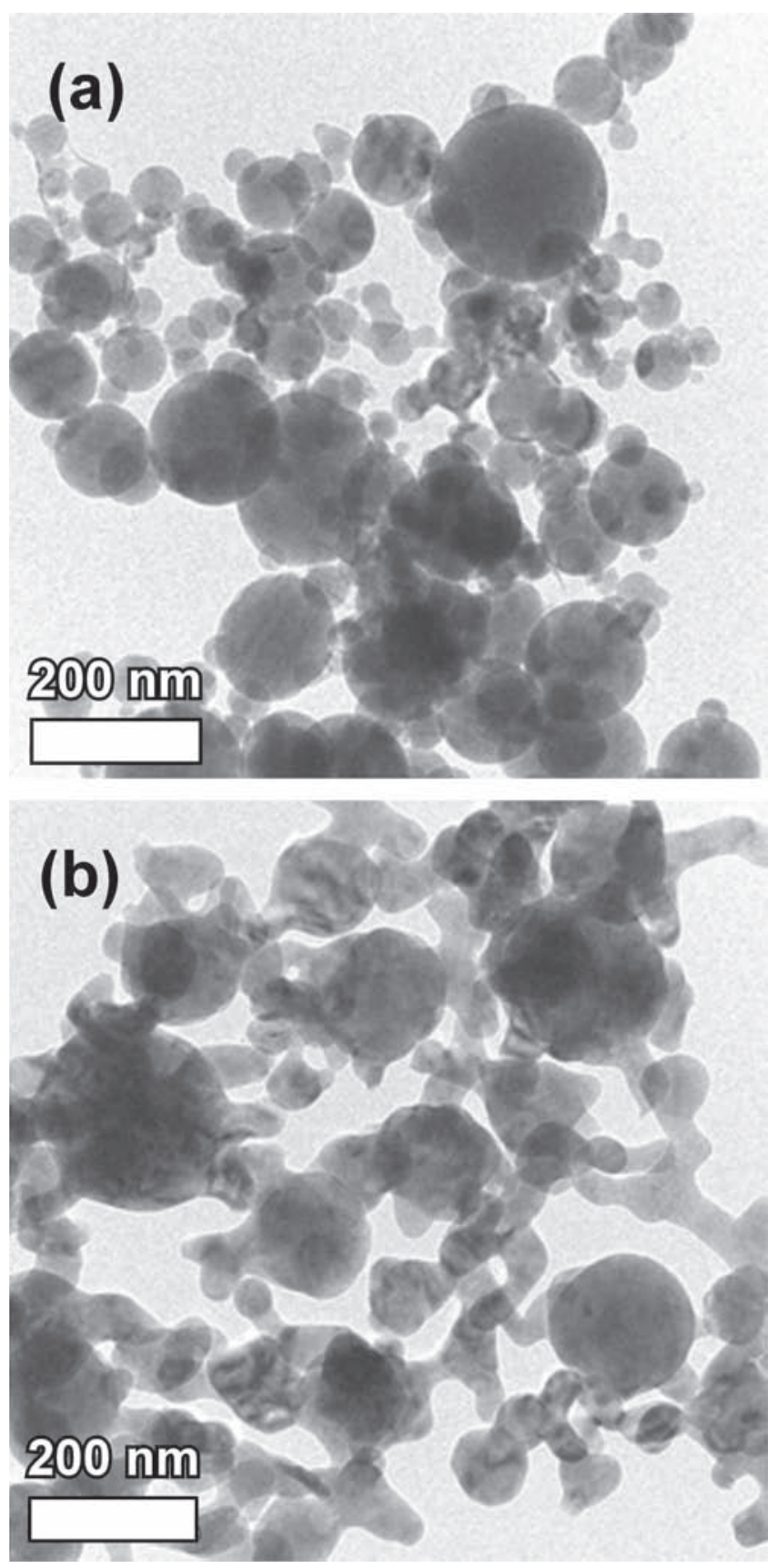

Fig. 2. Bright field TEM images of the (a) AR and (b) HT powder. Necking between the nano-particles in the HT powder was observed.

the specimen density was almost $40 \%$ for the specimen sintered at $100 \mathrm{MPa}$, and $25 \%$ for the specimen sintered at $2 \mathrm{MPa}$. The maximal shrinkage rate of $7.9 \times 10^{-1} \mathrm{~s}^{-1}$ was measured around $1380{ }^{\circ} \mathrm{C}$ and was identical at both pressures. This rapid shrinkage may be related to the enhanced diffusional processes at the particle surfaces, as will be explained in the discussion below. Density curves versus the SPS parameters for AR and HT powder compacts at $100 \mathrm{MPa}$ up to $1100^{\circ} \mathrm{C}$ were shown in Fig. 3b. It should be mentioned that no visible changes were observed in the particle size and shape after heating experiments at $500^{\circ} \mathrm{C}, 600^{\circ} \mathrm{C}$ and $700^{\circ} \mathrm{C}$ for $1 \mathrm{~h}$ in air. Therefore, diffusional processes during the pressure application at the 

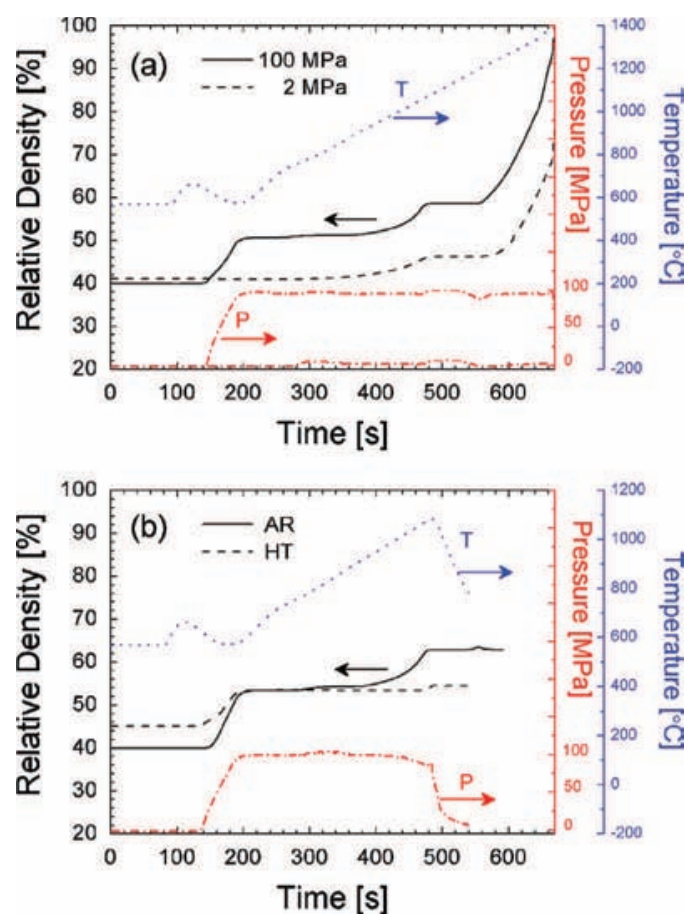

Fig. 3. Density, temperature and pressure versus SPS process time for (a) heating of the AR powder to $1400^{\circ} \mathrm{C}$ at $2 \mathrm{MPa}$ (black dashed curve) and $100 \mathrm{MPa}$ (black solid curve) pressure. (b) Heating of the AR (black solid curve) and HT (black dashed curve) powders to $1100^{\circ} \mathrm{C}$ at $100 \mathrm{MPa}$. Temperature and pressure are shown by the blue dotted line and the red dashed-dot lines, respectively. (For interpretation of the references to color in this text, the reader is referred to the web version of the article.)

SPS start (which was at $600^{\circ} \mathrm{C}$ ), before the start of the SPS heating, can be neglected. The shrinkage recorded for both powders at the beginning of the heating was associated with the pressure application, hence particle rearrangement. The HT powder did not exhibit any shrinkage during the heating up to $1100{ }^{\circ} \mathrm{C}$ and until the pressure was released (dashed-line curve in Fig. 3b).

The final densities of the AR powder sintered at 2 and $100 \mathrm{MPa}$ pressures versus SPS temperature are shown in Fig. 4a. As expected, the higher pressure used during heating by SPS to $1400{ }^{\circ} \mathrm{C}$, resulted in denser specimen, i.e. $71 \%$ versus $99 \%$ for 2 and $100 \mathrm{MPa}$ pressure, respectively. It was apparent that significant densification starts above $1200^{\circ} \mathrm{C}$, irrespective of the applied pressure (Fig. 4a). The green and the final relative densities of the compacts heated to $1100^{\circ} \mathrm{C}$ by SPS at different pressures $(2,32,64$ and $100 \mathrm{MPa})$, were shown in Fig. 4b. The green density is the density after pressure application prior to heating, and measured at $600^{\circ} \mathrm{C}$ (filled circles in Fig. 4b). Both densities (green and final) showed comparable linear dependence with the applied pressure, which indicates that similar densification mechanisms occur between these temperatures, irrespective of the applied pressure. This further indicates that the increase in density below $1100{ }^{\circ} \mathrm{C}$ is mainly due to the particle rearrangement caused by the pressure increase $(\sim 14 \%)$, rather than by temperature increase $(\sim 7 \%)$.

HRSEM images from the fracture surfaces of the specimens sintered to different final temperatures allowed the investigation
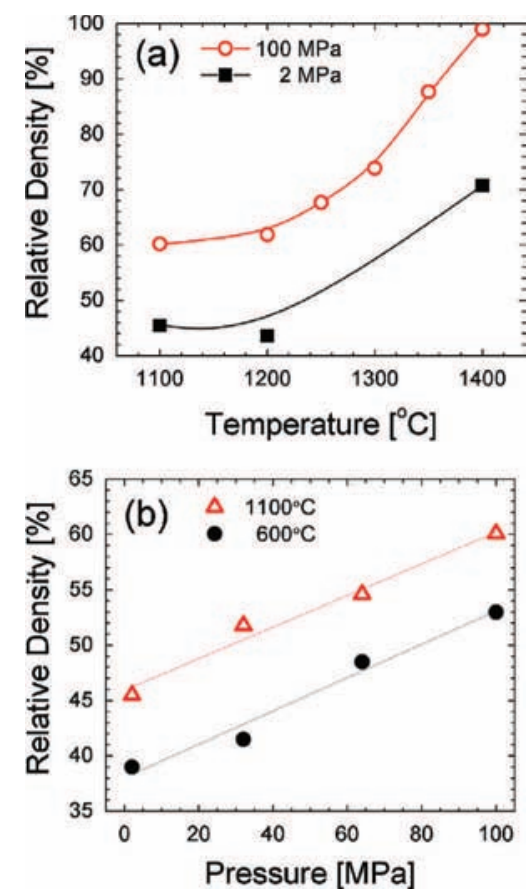

Fig. 4. (a) Final densities of the AR powder specimens versus SPS temperature at 2 and $100 \mathrm{MPa}$. (b) Green (circles) and final (triangles) relative densities of the specimens heated by SPS to $1100{ }^{\circ} \mathrm{C}$ show linear dependence with pressure. Density increased by $14 \%$ and $7 \%$ due to the pressure and temperature increase, respectively. (For interpretation of the references to color in the figure legend, the reader is referred to the web version of the article.)

of the microstructure evolution during the SPS. The sintered microstructure was homogeneous, where the particle morphology changed with the temperature increase from spherical to polyhedral grain shape (Fig. $5 \mathrm{a}-\mathrm{c}$ ). At $1200^{\circ} \mathrm{C}$ many rod-like features bridging over the gaps between the particles/grains were observed (inserts in Fig. 5a). These features resembled material jets between the grains, most probably formed by the local spark; they were absent at $1300^{\circ} \mathrm{C}$ and $1400^{\circ} \mathrm{C}$ treatments. An increase in the grain size with SPS temperature increase was also observed (Table 1). The solid frame of the partially sintered compacts with well-developed necks was observed in TEM (Fig. 6a). Furthermore, unusual features were observed within the microstructure of the partially sintered compacts below $1200^{\circ} \mathrm{C}$, in both TEM and HRSEM images. These were characterized by narrow rod-shaped amorphous material jets, connecting between the much larger adjacent particles around a cavity (arrowed in Fig. 6a and b, respectively). The amorphous nature of the material jets was confirmed by tilting experiments in TEM, where no contrast changes were observed in the material jets, while significant changes were observed in the crystalline particles connecting these jets. These rods do not represent conventional necks since they connect between adjacent grains which are far apart; they can be clearly distinguished from the conventional necks, by their unusual large meniscus which does not show any faceting. The large meniscus geometry of the rod-shape jet material connecting between distant particles can be therefore associated with the model of liquid phase sintering. ${ }^{22}$ These rods are most probably the remnant of the liquid flow under the local field present during the plasma 

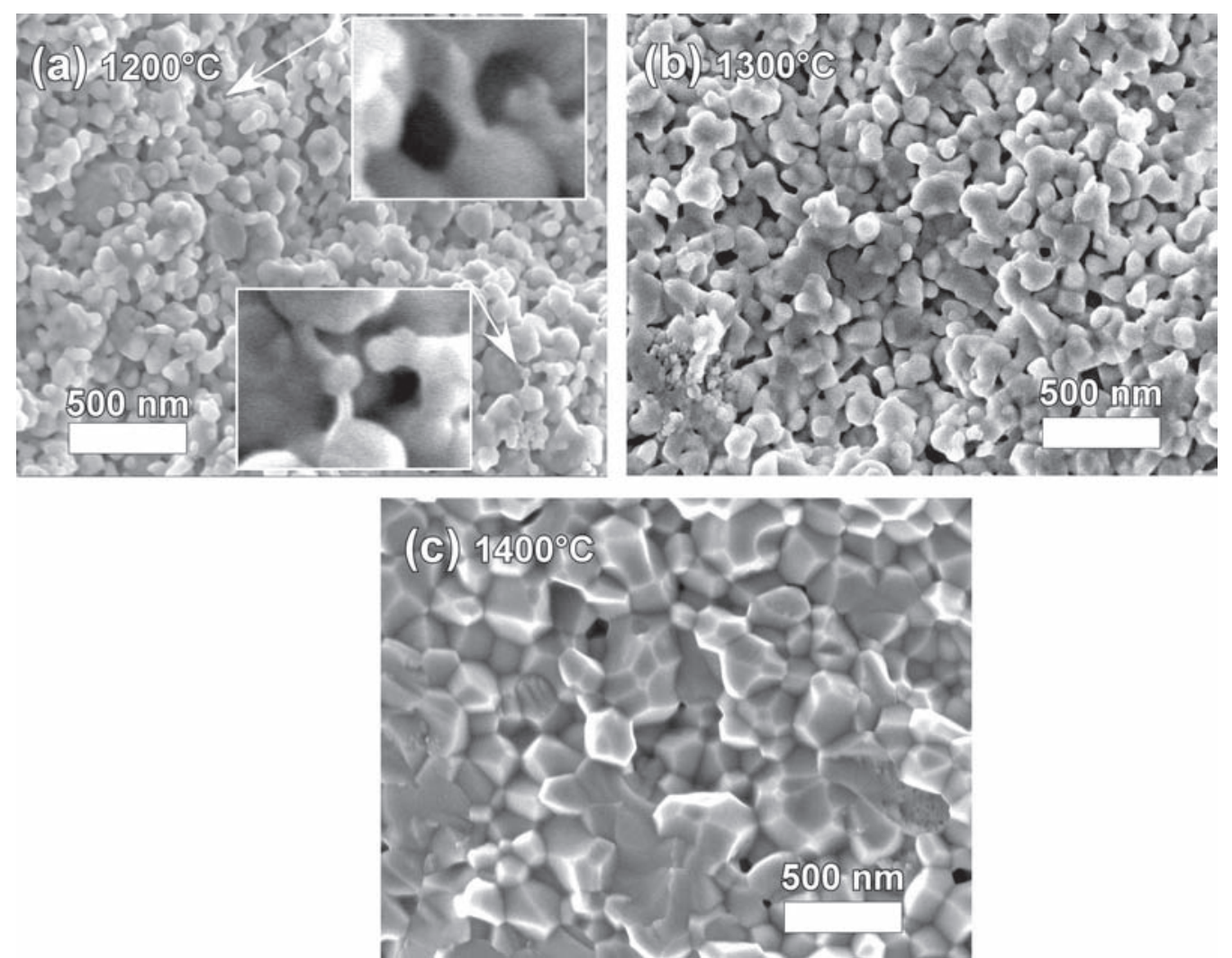

Fig. 5. HRSEM images of the fracture surface of YAG specimens densified by SPS at (a) $1200^{\circ} \mathrm{C}$, (b) $1300^{\circ} \mathrm{C}$ and (c) $1400^{\circ} \mathrm{C}$. Several rod-like features bridging over the gaps between the grains/particles are shown by inserts in (a).

sintering. As such features may possibly be an artifact due to the ion milling for TEM preparation, their presence in the SEM images (Fig. 6b) negates this possibility. It should be mentioned that these rod-shape material jets were also observed in HRSEM specimens without carbon coating; therefore, they cannot be a residue or an artifact of the carbon coating. EDS point analysis in HRSEM, taken at several loci at the broken specimen surfaces, showed peaks for $\mathrm{Y}, \mathrm{Al}, \mathrm{O}$ and $\mathrm{C}$ (from the carbon coating) where no impurities were found.

In addition, the denser specimens sintered at $1250^{\circ} \mathrm{C}$ and $1300^{\circ} \mathrm{C}$ exhibited several partially dense nano-clusters, within which aligned and well-organized individual original particles were preserved at the fracture surfaces (i.e. Fig. 6c). Such particle alignment may be the remnant of the strong local electric field during the SPS process. This observed microstructure evolution and the overall densification behavior will be discussed below, with respect to particle surface softening due to plasma and the intensified local electric field.

\section{Discussion}

As was shown above, the initial shrinkage and densification of the nc-YAG compacts started due to the pressure application at $\sim 600{ }^{\circ} \mathrm{C}$, after the jump to this temperature was stabilized (Fig. 3). Shrinkage ceased once the applied pressure reached its maximum value, irrespective of temperature. Further shrinkage was observed only at $\sim 950^{\circ} \mathrm{C}$ in the AR powder, and the shrinkage rate increased with temperature. At first, a similar shrinkage leading to $\sim 7 \%$ increase in density was observed at all pressures (Fig. 4b), which indicates that similar densification mechanisms occurred between $600^{\circ} \mathrm{C}$ and $1100^{\circ} \mathrm{C}$. Between $1060^{\circ} \mathrm{C}$ and $1200^{\circ} \mathrm{C}$ the shrinkage experienced discontinuity, again irrespective of the applied pressure. Following the DSC results, the shrinkage at $\sim 950^{\circ} \mathrm{C}$ can be related to crystallization/nucleation of the cubic YAG phase. ${ }^{18-20}$ This temperature is a little higher than measured in the DSC $\left(895^{\circ} \mathrm{C}\right)$; however, the temperatures during the SPS process are measured at the graphite die, and may be higher by several degrees from the temperature inside the non-conductive compact. Therefore, a possible scenario for the shrinkage start may be as the following: The particles pack at the beginning of the process by rearrangement due to the applied pressure, and get jammed due to frictional forces between them. Increase in the applied pressure overcomes the frictional forces, hence a linear increase in the density (up to $14 \%$ ). This persists until crystallization of the cubic YAG occurs, which releases the jam by supplying exothermic energy to the particle surfaces, and enables further shrinkage of the specimen under the pressure.

The discontinuity in the shrinkage between $1060^{\circ} \mathrm{C}$ and $1200{ }^{\circ} \mathrm{C}$ should be related to the Perovskite to Garnet phase transformation, which is accompanied by $17 \%$ volume expansion, hence opposing the ram displacement and leading to the small oscillations recorded in the pressure. When the phase transition went to completion further fast shrinkage occurred, whereby the shrinkage rate increased between $1200^{\circ} \mathrm{C}$ and $1400{ }^{\circ} \mathrm{C}$. The highest shrinkage rate was observed at $1380{ }^{\circ} \mathrm{C}$, 

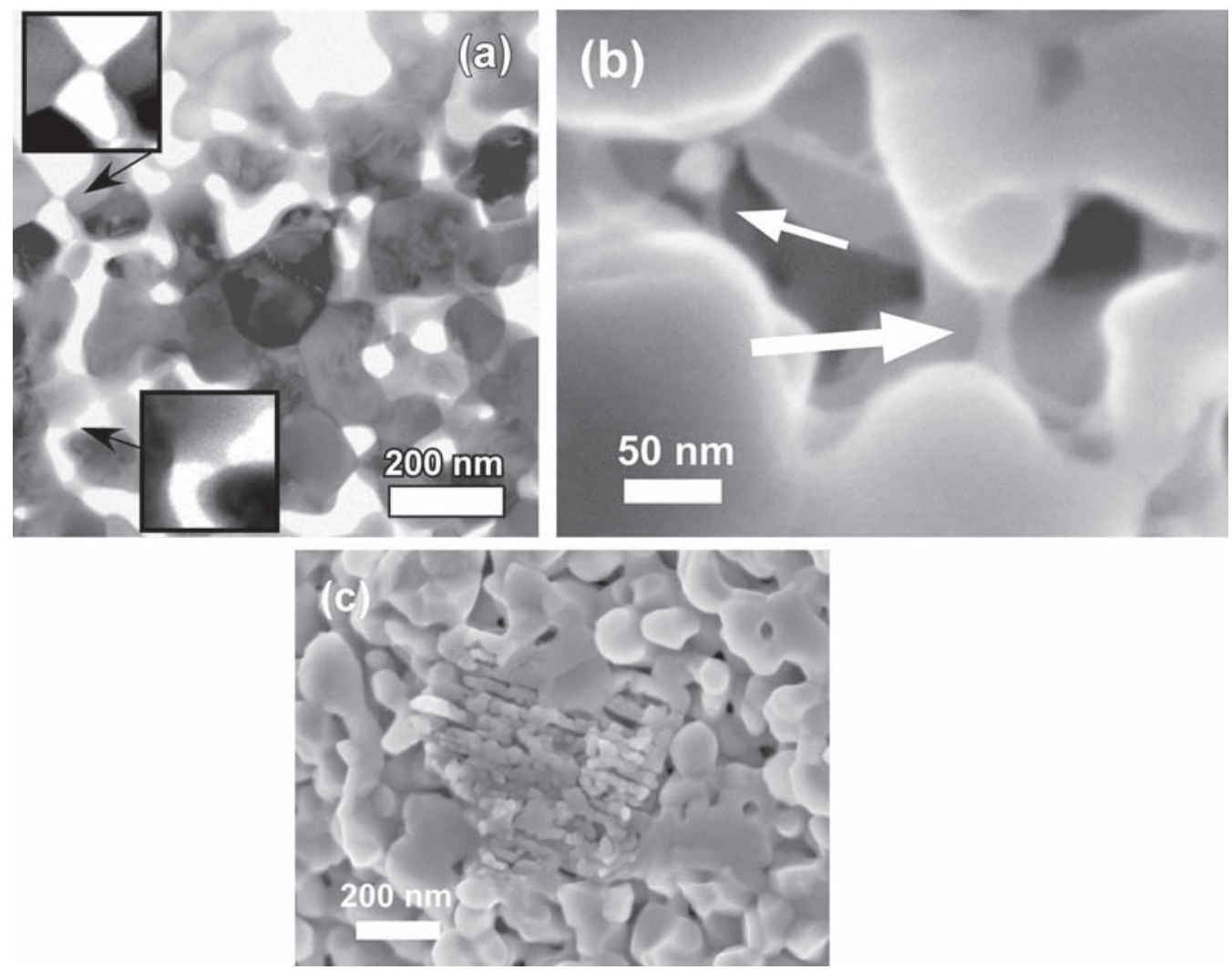

Fig. 6. (a) Bright Field TEM and (b) HRSEM images from the specimens fabricated at $1100^{\circ} \mathrm{C}$ and $1200^{\circ} \mathrm{C}$, respectively, showing the material-jets connecting adjacent particles over the gaps in the partially sintered compact after SPS at $100 \mathrm{MPa}$. (c) Aligned nano-particles in partially dense clusters left at $1300{ }^{\circ} \mathrm{C}$ and $100 \mathrm{MPa}$ SPS treatment.

similar to another SPS study of nano-YAG, where the maximal rate was recorded at $1400^{\circ} \mathrm{C} .{ }^{23}$ However, at this temperature, rod-shape amorphous material jets were absent. The material jets manifest that liquid was formed during the process. The high shrinkage rate above $1200{ }^{\circ} \mathrm{C}$ can be related to the viscous sliding/rotation of the nano-particles, their coalescence into subgrain clusters, followed by hierarchical coalescence and growth of the clusters. ${ }^{7}$ In this respect, the high densification rate should be associated with particle surface softening due to the plasma formation at the cavities. Analysis of the grain growth kinetics in nc-YAG was consistent with diffusion through a liquid layer. ${ }^{7}$ Moreover, the activation energy showed a close value to the enthalpy of fusion of YAG, which is equivalent to the activation energy for maintaining the liquid and is comparable to the activation energy for grain growth through a liquid layer. ${ }^{7}$ The tendency for nano-grains coalescence by rotation/sliding during SPS was observed for $\gamma-\mathrm{Al}_{2} \mathrm{O}_{3}{ }^{24}$ and spherical $\alpha-\mathrm{Al}_{2} \mathrm{O}_{3}{ }^{25}$ powders, and for SPS of $\mathrm{SrTiO}_{3}$ nano-powders with cubical morphology. ${ }^{26}$ Above $1350^{\circ} \mathrm{C}$ significant grain growth of YAG nano-particles started, the kinetics of which did not follow normal grain growth behavior. ${ }^{7}$ This was consistent with other SPS studies on nano-YAG at the corresponding temperature range. ${ }^{27}$ The fact that the maximum shrinkage rate was at $1380^{\circ} \mathrm{C}$, where the specimens are very dense (above $90 \%$ ) may be due to the easy super-cooled nature of liquid YAG below its melting point. ${ }^{28,29}$ Therefore, the liquid formed at the lower temperature has been preserved metastabley at higher temperatures.
Recently, LiF particle compacts subjected to SPS exhibited microstructure with partially melted grains and significant material jets, confirming the existence of spark and plasma. ${ }^{13}$ Similar microstructural evidences were reported for $\mathrm{TiB}_{2}, \mathrm{Cu}$ and $\mathrm{Ti}_{1} \mathrm{TiB}_{2}$ mixture. ${ }^{30}$ A preliminary model, developed for the evaluation of the plasma conditions in dielectric ceramics, ${ }^{14}$ was used to estimate the temperature range for plasma formation under $100 \mathrm{MPa}$ applied pressure in YAG (Fig. 7). When sufficient surface conductivity is gained, spark and plasma may form at the cavities between the particles due to surface discharges, as long as the microstructure is not continuous, thus, as long as no plastic deformation has occurred. Since YAG crystals are very hard to deform plastically, the onset temperature for plastic deformation under $100 \mathrm{MPa}$ is set around $1850{ }^{\circ} \mathrm{C} .{ }^{31}$ This leaves the temperature range window for plasma formation to dominate at lower temperatures as low as $500^{\circ} \mathrm{C}$ (Fig. 7). Although the plasma window boundaries were determined by the criterion of $10^{-9}-10^{-5} \Omega^{-1} \mathrm{~cm}^{-1}$ conductivity (Fig. 7 and Ref. [14]), its upper temperature boundary is limited only by the lower temperature of the plastic deformation window. Consequently, plasma may be active also at temperatures above $900{ }^{\circ} \mathrm{C}$ in this system provided interparticle gaps exist. Therefore, YAG is one of the oxide candidates for which plasma formation is most probable before the densification proceeds by the plastic deformation. This explains the existence of the observed amorphous material-jets between nano-particles in the partially dense microstructure, formed from surface melting 


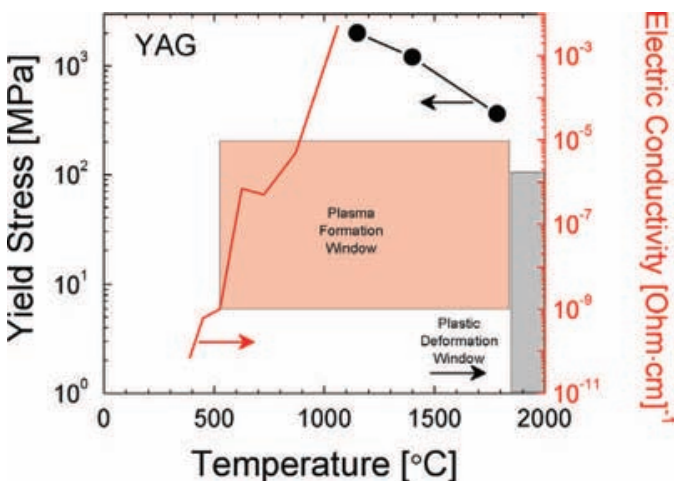

Fig. 7. Plastic yield - plasma windows diagram calculated for YAG powder at $100 \mathrm{MPa}$.

after sparking and plasma formation. However, the lower extent and frequency to find material jets in YAG, such as the ones shown in Fig. 6b compared to $\mathrm{LiF}^{13}$ may be referred to the high melting temperature of YAG $\left(1970{ }^{\circ} \mathrm{C}\right)$ and its high melt viscosity $^{32}$ relative to $\mathrm{LiF}$, as well as its nano-size particles. In this respect, several different investigations on SPS of alumina revealed dense microstructures with no traces of liquid. However, SEM images from fracture surfaces of $\alpha$-alumina, sintered by one-step pressureless SPS, exhibited atomic terraces at the grain surfaces exposed within the cavities, characteristic of the evaporation-condensation mechanism. ${ }^{33}$ The electrical resistivity and the yield stress of $\mathrm{Al}_{2} \mathrm{O}_{3}$ and their change with temperature, significantly depend on the composition and the polymorph content. Following the data used for pure $\mathrm{Al}_{2} \mathrm{O}_{3}$, the SPS temperature window was estimated to start at $900{ }^{\circ} \mathrm{C}$ at the pressure of $100 \mathrm{MPa} .{ }^{14}$

The well-organized particle clusters found in the partially dense regions in the otherwise dense compacts (Fig. 6c) emphasize the strong effect of the applied electric field in SPS. It appears that the electric field asserts forces which are strong enough to restrict the arrangement of a whole group of nanoparticles. Yet, such an alignment necessitates sufficient mobility of the individual nano-particles. This is possible due to surface pre-melting and the presence of a viscous layer at which the nano-particles can slide and rotate to find their position, while the frictional stresses relax.

Finally, the necks formed in the heat treated (HT) powder hinder significant rearrangement and sliding of the particles compared to the AR powder. Furthermore, increase in the particle connectivity is expected to decrease the probability for surface discharges and plasma formation due to the presence of a continuous and rigid skeleton. This in turn provides a continuous path for the electric current transfer; charging and discharge at the particle surfaces, which are necessary for spark and plasma, are barely feasible in such a microstructure. The lack of corresponding high temperature shrinkage in HT powder seems to be a manifestation of this phenomenon.

\section{Conclusions}

Densification of YAG nano-powders by the SPS method was investigated at different temperature and pressure conditions.
Densification first takes place by particle rearrangement due to the pressure applied at $600^{\circ} \mathrm{C}$. After compaction, shrinkage starts in the AR powder due to crystallization and nucleation of amorphous YAG at $950{ }^{\circ} \mathrm{C}$, though it stagnates during the phase transformation of YAP to YAG between $1060^{\circ} \mathrm{C}$ and $1200^{\circ} \mathrm{C}$. The rapid densification observed above $1200^{\circ} \mathrm{C}$ was related to the densification by nano-particle sliding and rotation, assisted by surface softening due to the plasma. Material jets connecting over gaps between the spherical nano-particles are evidence for liquid formation and the proof for the existence of sparking and plasma. The occurrence of plasma was explained by means of plasma formation-plastic deformation diagram. Clusters of aligned nano-particles preserved in partially dense regions, in the otherwise dense specimens, revealed the electric field effect during the process. The liquid formed in the partially dense compacts may be metastabley retained at higher temperatures and assist the enhanced densification. The more rigid skeleton and connected microstructure of the HT powder leaves less possibilities for surface charging and discharging, and therefore the effects of the plasma do not occur.

\section{Acknowledgement}

R. Marder acknowledges the support of the fellowship from the Women in Science program of the Israel Ministry of Science and Technology.

\section{References}

1. Munir ZA, Quach DV, Ohyanagi M. Electric current activation of sintering: a review of the pulsed electric current sintering process. J Am Ceram Soc 2011;94:1-19.

2. Grasso S, Sakka Y, Maizza G. Electric current activated/assisted sintering (ECAS): a review of patents 1906-2008. Sci Technol Adv Mater 2009; 10:053001.

3. Yoshida H, Morita K, Kim BN, Hiraga K, Kodo M, Soga K, Yamamoto T. Densification of nanocrystalline yttria by low temperature spark plasma sintering. J Am Ceram Soc 2008;91:1707-10.

4. Cologna M, Rashkova B, Raj R. Flash sintering of nanograin zirconia in $<5 \mathrm{~s}$ at $850^{\circ} \mathrm{C}$. J Am Ceram Soc 2010;93:3556-9.

5. Conrad H, Wang J. Equivalence of AC and DC electric field on retarding grain growth in yttria-stabilized zirconia. Scr Mater 2014;72-73:33-4.

6. Tamari N, Tanaka T, Tanaka K, Kondoh I, Kawahara M, Tokita M. Effect of spark plasma sintering on densification and mechanical properties of silicon carbide. J Ceram Soc Jpn 1995;103:740-2.

7. Chaim R, Marder-Jeackel R, Shen JZ. Transparent YAG ceramics by surface softening of nanoparticles in spark plasma sintering. Mater Sci Eng A 2006;429:74-8.

8. Wu YJ, Li J, Chen XM, Kakegawa K. Densification and microstructure of $\mathrm{PbTiO}_{3}$ ceramics prepared by spark plasma sintering. Mater Sci Eng A 2010;527:5157-60.

9. Narayan J. Grain growth model for electric field-assisted processing and flash sintering of materials. Scr Mater 2013;68:785-8.

10. Tokita M. Mechanism of spark plasma sintering and its application to ceramics. New Ceram 1997;10:43-53 [in Japanese].

11. Kumeda K, Nakamura Y, Takata A, Ishizaki K. Surface observation of pulsed electric current sintered alumina balls. J Ceram Soc Jpn 1999;107:187-9.

12. Steil MC, Marinha D, Aman Y, Gomes JRC, Kleitz M. From conventional ac flash-sintering of YSZ to hyper-flash and double flash. J Eur Ceram Soc 2013;33:2093-101.

13. Marder R, Estournès C, Chevallier G, Chaim R. Plasma in spark plasma sintering of ceramic particle compacts. Scr Mater 2014;82:57-60. 
14. Chaim R. Electric field effects during spark plasma sintering of ceramic nanoparticles. J Mater Sci 2013;48:502-10.

15. Marder R, Estournes C, Chevallier G, Kalabukhov S, Chaim R. Spark plasma sintering of ductile ceramic particles: study of LiF. J Mater Sci 2014:49:5237-45.

16. Marder R, Chaim R, Chevallier G, Estournes C. Effect of $1 \mathrm{wt} \%$ LiF additive on the densification of nanocrystalline $\mathrm{Y}_{2} \mathrm{O}_{3}$ ceramics by spark plasma sintering. J Eur Ceram Soc 2011;31:1057-66.

17. Laine RM, Marchal J, Sun H, Pan XQ. A new $\mathrm{Y}_{3} \mathrm{Al}_{5} \mathrm{O}_{12}$ phase produced by liquid-feed flame spray pyrolysis (LF-FSP). Adv Mater 2005;17: 830-3.

18. Li X, Liu H, Wang J, Zhang X, Cui H. Preparation and properties of YAG nano-sized powder from different precipitating agent. Opt Mater 2004;25:407-12.

19. Ru Y, Jie Q, Min L, Guoqiang L. Synthesis of yttrium aluminum garnet (YAG) powder by homogeneous precipitation combined with supercritical carbon dioxide or ethanol fluid drying. J Eur Ceram Soc 2008;28:2903-14.

20. Yamaguchi O, Takeoka K, Hirota K, Takano H, Hayashida A. Formation of alkoxy-derived yttrium aluminium oxides. J Mater Sci 1992;27:1261-4.

21. Azis RS, Holland D, Smith ME, Howes A, Hashim M, Zakaria A, Hassan J, Saiden NM, Ikhwan MK. DTA/TG, XRD, and ${ }^{27} \mathrm{Al}$ MAS NMR of yttrium aluminium garnet, $\mathrm{Y}_{3} \mathrm{Al}_{5} \mathrm{O}_{12}$ by sol-gel synthesis. J Aust Ceram Soc 2013;49:74-80.

22. Kang SL. Sintering-densification, grain growth and microstructure. Oxford: Elsevier; 2005.

23. Suárez M, Fernández A, Menéndez JL, Torrecillas R. Transparent yttrium aluminium garnet obtained by spark plasma sintering of lyophilized gels. $J$ Nanomater 2009;2009:1-5.
24. Shen Z, Xiong Y, Höche T, Salamon D, Fu Z, Belova L. Ordered coalescence of nanocrystals: a path to strong macroporous nanoceramics. Nanotechnology 2010;21:205602.

25. Morales-Rodríguez A, Poyato R, Gallardo-López A, Muñoz A, DomínguezRodríguez A. Evidence of nanograin cluster coalescence in spark plasma sintered $\alpha-\mathrm{Al}_{2} \mathrm{O}_{3}$. Scr Mater 2013;69:529-32.

26. Hu J, Shen Z. Grain growth by multiple ordered coalescence of nanocrystals during spark plasma sintering of $\mathrm{SrTiO}_{3}$ nanopowders. Acta Mater 2012;60:6405-12.

27. Palmero P, Bonelli B, Fantozzi G, Spina G, Bonnefont G, Montanaro L, Chevalier J. Surface and mechanical properties of transparent polycrystalline YAG fabricated by SPS. Mater Res Bull 2013;48:2589-97.

28. Nordine PC, Weber JKR, Abadie JG. Properties of high temperature melts using levitation. Pure Appl Chem 2000;72:2127-36.

29. Tangeman JA, Phillips BL, Nordine PC, Weber JKR. Thermodynamics and structure of single- and two-phase yttria-alumina glasses. J Phys Chem B 2004;108:10663-71.

30. Zhang Z, Liu ZF, Lu JF, Shen XB, Wang FC, Wang YD. The sintering mechanism in spark plasma sintering - proof of the existence of spark discharge. Scr Mater 2014;81:56-9.

31. Chaim R, Marder R, Estournés C, Shen Z. Densification and preservation of ceramic nanocrystalline character by spark plasma sintering. Adv Appl Ceram 2012;111:280-5.

32. Weber RJK, Felten JJ, Cho B, Nordine PC. Glass fibres of pure and erbium- or neodymium-doped yttria-alumina compositions. Nature 1998:393:769-71.

33. Salamon D, Shen Z. Pressure-less spark plasma sintering of alumina. Mater Sci Eng A 2008;475:105-7. 